\title{
BIBLE TRANSLATION - A LIGHTHOUSE AND A LIBRARY FOR THE PROMOTION AND PRESERVATION OF LANGUAGE AND 'LITERATURE' IN AFRICA: THE EXAMPLE OF CHINYANJA ${ }^{1}$
}

\author{
Ernst R Wendland \\ Department of Ancient Studies \\ University of Stellenbosch
}

\begin{abstract}
In this article I explore several implications of the thematic metaphorical terms "lighthouse" and "library" with reference to three translations of the complete Scriptures that have been made in the Chinyanja language of Malawi, Zambia, and Mozambique. How did these translations, one begun over a century ago, serve both to promote (enlighten, show the way, reveal the rocks) and also to preserve (act as a reservoir and repository for) the language and culture of the Chinyanja-speaking peoples of this south-central African region? My survey describes some of the major challenges, difficulties, and setbacks encountered along the way in contrast to certain outstanding successes that were achieved and new initiatives undertaken during this long history, which continues to be written in the new millennium. Several linguistic aspects of this progressive development are briefly examined in a comparative manner with reference to a number of Scripture passages as they appear in the most literal and most idiomatic Chinyanja versions. I conclude by summarizing the potential of mother-tongue Bible translation for enlarging, by way of preservation and promotion, the overall communication resources of any given language-culture, especially one that does not have a great corpus of published literature.
\end{abstract}

\section{Introduction: The Influence of Bible Translation in Africa}

There are numerous reports - some documented, others not - which record the great damage that was done by many early missionaries to the diverse modes of indigenous cultural expression among African peoples. Such injury seriously affected the growth also of African languages and literatures in different degrees, depending on the situation, for example, through inadequately conceived Western-oriented orthographies and grammars or the general discouragement, sometimes banning, of publicly performed traditional oral art forms. The question that I would like to briefly address in this article concerns the common missionary practice of Bible translation: Given the fact that Christianity and its holy book were initially alien to the peoples of Black Africa (south of the Sahara) in terms of both form and content ${ }^{2}$ to what extent might the Bible have served in a patently positive way

1. This article was originally prepared as a paper for summary presentation at the African Literature Association Annual Meeting (Alexandria, Egypt, March 19-22, 2003) as part of a United Bible Societies panel entitled: "Bible Translation: A Lighthouse and a Library for African Languages and Literature". Chinyanja is a major southeastern Bantu language (Guthrie Zone N, Group 30) that is spoken as a first or second language by some twelve million people, primarily in the countries of Malawi, Zambia, and Mozambique.

2. Notice the geographical specification. I am not claiming that Christianity or the Bible had no early influence at all in Africa. Indeed, there was a strong Jewish presence (along with their Scriptures, the Hebrew Tanakh and its translation into Greek, commonly known as the Septuagint) on the continent at least six centuries 
either as a "lighthouse" or a "library" to promote the development of African languages and literatures (or their oral traditions)? ? $^{3}$

The research scholar David Barrett was one of the first to call attention to the significant contribution that Bible translation appears to have made to the linguistic, social, and cultural development of Africa:

Vernacular scriptures have far greater power to communicate and create religious dynamic than versions in linguae francae such as Swahili, Hausa, Arabic, French, or English, which have been in circulation in many areas long before the onset of [religious] independency without fomenting disaffection. The vernacular translation enables the ethnic group concerned to grasp the inner meanings of ... profound and intricate biblical doctrines. ... Further, it is clear that these vernacular translations - with all the attendant expenditure of effort on orthography, grammars, dictionaries, and studies of tribal cultures - have contributed markedly to the recovery by Africans of the cultural identity of their tribe, later expressed in such bodies as tribal political parties, welfare societies, and particularly in tribal independent churches (1968:133).

This theme was later documented in a most thorough and eloquent manner by the Gambian scholar, Lamin Sanneh in his seminal work, Translating the Message (1989). A few pertinent quotes will serve to trace the essence of Sanneh's influential argument as it applies to Bible translation in Africa (cf. Wendland 1998:210-216):

$[\mathrm{M}]$ issionaries became ultimately helpless in the face of the overwhelming contextual repercussions of translation. ... [H] owever much mission may have been conceived as the arm of European political expansion, missionaries still had to rely on indigenous [African] languages to preach their message, and this created a distinction between European culture and the indigenous traditions. ... [T] he new interest in creating vernacular Scriptures for societies that had no [written] Scriptures of their own ushered in a fundamental religious revolution, with new religious structures coming in to preside over the changes. One of the most dramatic changes was undoubtedly the popular, mass participation of Africans in this process (158-159; my text alterations are in brackets).

The process, then, of acquiring knowledge of the indigenous languages brought missionaries into the sphere of religious customs. ... [Bishop Samuel Ajayi] Crowther was perceptive enough to realize that translation led naturally to developing a deeper appreciation for the entire culture. ...As long as missionaries were committed to translation, so long would vernacular concepts and usage continue to determine the assimilation of Christianity, including the understanding of God by more inclusive criteria.

...Thoughtful missionaries [not all of them were!] understood that God had preceded them in Africa ...that translation involved esteem for the vernacular culture, if not surrender to it, that the authentic forms of the culture, consecrated by the elders, constituted the most promising signs for the Christian cause, and that, finally, linguistic investigations and the

before the Christian era. However, this was limited more or less to the north-eastern corner of "Egypt," Alexandria in particular, where the headquarters for the "LXX project" was based, and also to various regions of "Ethiopia" from an even earlier time (cf. Neusner and Green 1996:183, 208).

3. I am not very comfortable using the general term "literature" to refer also to various types of orally performed art, e.g., myths, folktales, historical narratives, proverbs, riddles, songs, etc. Some scholars have used "orature" to designate these verbal artistic genres, but that term does not seem to have gained very wide acceptance. In any case, this is not a major issue in the present article where I am focusing on the written forms of African languages. I am operating under the assumption that translations of the Scriptures into the various languages of Africa do constitute valid instances of literature and that these texts may therefore also be technically analyzed and qualitatively assessed according to standard literary criteria and procedures. For some explanatory justification for this position, see Wendland 2002. 
systematic inventory of indigenous resources were likely to touch off wider and longerlasting repercussions in the culture (165-167).

In undertaking translation, missionaries demonstrated the limited usefulness of European languages, while indigenous Africans, confronted with the stimulus of missionary interest, received the Scriptures as written warrantee for the vernacular. ... From the heightened awareness occasioned by the availability of the written Scriptures in the vernacular, local converts appropriated the gospel without running it through Western filters first $(174,177)$.

Indeed, it is most significant that these early European missionaries made abundant use of many African vernaculars - not the few languages of colonization (English, French, Portuguese, Spanish), for their work of evangelization and education. The Catholics by and large did not even insist upon a Latin liturgy! This development, undoubtedly encouraged by the need to translate the Scriptures into the local vernacular, certainly served to promote the study and use of these languages and their associated cultures. However, this evaluation and conclusion is not quite so straightforward; an additional complicating factor needs to be considered - that is, the particular nature or style of these mission-sponsored Bible translations.

The various possible translation types range along a broad continuum from the woodenly literal to those versions that attempt to provide an idiomatic re-expression of the original Hebrew or Greek text (often mediated more or less by the prevailing lingua franca such as French or English). ${ }^{4}$ It is generally true that the more naturally rendered, "domesticated" versions have come to the fore only in the past thirty years or so, in response to a movement within the Bibles Societies and related agencies for a more meaningful manner of translation. ${ }^{5}$ Before that time most versions, the early missionary productions in particular, tended to be rather literal, or "foreignized," in terms of style. This was in keeping with the belief that such a "formal correspondence" text (Nida \& Taber 1969:22) was a more "faithful" sort of rendering. The problem is that some of these literally worded texts turned out to be so awfully "foreign" sounding, both linguistically and conceptually, that they were often virtually unintelligible to the majority of their readers (and hearers). Examples of this phenomenon will be illustrated during our subsequent discussion of the three extant Chinyanja versions.

The point is that statements like the following, in blanket reference to "these vernacular translations" (Barrett 1968:133), need to be more closely qualified, depending upon the local circumstances that applied when a given version was made:

African informants, advancing upon the accumulating evidence of field investigations, swept away such artificial [literal and scholastic] contrivances and the assumptions on which they were based. ...The distinguishing mark of scriptural translation has been the effort to come as close as possible to the speech of the common people (Sanneh ibid:171, 192, added italics).

4. I discuss such a virtual translation "continuum" in Wendland 2002:180-183.

5. One of the first popular and influential presentations of this new, meaning-oriented approach to Bible translation was Nida \& Taber (1969). For a recent review of current United Bible Societies' thinking concerning the preparation of different Bible translation for different audiences, see Wilt 2003.

6. "Foreignizing... means taking the reader over to the foreign culture, making him or her see the (cultural and linguistics) differences. ...A foreigning strategy seeks to evoke a sense of the foreign" (Lawrence Venuti, cited in Katan 1999:156). A "domesticating" strategy of translation, on the other hand, operates in the opposite manner; it seeks to transport a foreign text over to the local culture, allowing the original author to express him- or herself naturally in the target language. A "foreignized" translation tends to be more literal in nature, while a "domesticated" version aims to be more idiomatic in style. 
However, in many pioneer settings these "African informants" remained very much that in effect, mere human mouth-pieces or dictionaries, with their words completely subject to the interpretation of the Western missionaries who controlled the entire translation process. The result of this normally very literalistic procedure, as already noted, would frequently turn out to be very far away from "the speech of the common people." Furthermore, these early texts and their officially "approved" interpretations were also strongly supported by the extensive educational and indoctrinating machinery of the typical mission church. There was not much room for deviation from the standard ecclesiastical line, either in terms of the form of the biblical text or its perceived content. Substantial changes in this scenario began to occur only during the era of political independence in the 1950-60s, when African mother-tongue translators were finally allowed and empowered to carry out this challenging work of literary text-transformation.

The preceding qualification does not deny or detract from Sanneh's basic thesis; ${ }^{7}$ nor does it mean that early, missionary-generated Bible translations had relatively little impact on the promotion of African languages and verbal art forms. My point is simply that the outcome of this linguistic and cultural development was somewhat less than, or diminished from, what it might have taken place had a more enlightened, target-language (TL) oriented translation policy been followed from the very beginning - including a priority given to the use of mother-tongue translators as fuller partners in such projects.

The following survey outlines a little "case study" that illustrates the variegated contribution that Bible translation has made over the years, specifically with regard to the Chinyanja language and literature. ${ }^{8} \mathrm{I}$ intend to explore this subject according to the two metaphorical categories that are suggested by the theme of the $29^{\text {th }}$ annual conference of the African Language Association: "Of Lighthouses and Libraries: History ReLit." After a short historical introduction to Bible translation in Chinyanja, I will overview the impact that this multifaceted, long-term process appears to have had in terms of general as well as specific aspects of both language preservation (i.e., like a "library") and also illumination (like a "lighthouse").

\section{Historical Background: A (Short) Tale of Three Translations}

Three complete Bibles are currently available in the Chinyanja language: the Buku Lopatulika (BL, "Sacred Book"), Malembo Oyera (MO, "Holy Letters"), and Buku Loyera (BY, "Holy Book"). The following is a thumbnail sketch of their respective histories and interrelationships:?

7. Sanneh also points out a number of related areas within the broad framework of a given society or linguistic community where Bible translation and ancillary activities provided much needed stimulation as well as guidance: local religious reform, renewal, or revival movements; Christian inter-church dialogue and cooperation; an indigenous mode of biblical hermeneutics; basic literacy and general education; various ethnic studies and cultural promotions; community social action and national political activism (cf. Wendland 1998:212-213).

8. As far as the continent as a whole is concerned, a recent United Bible Societies report (published on their website: www.biblesociety.org ) noted that 207 Scripture portions, 289 New Testaments, and 151 Bibles had been published in/for Africa by the end of 2002. This covers virtually all of the "major" tongues (i.e., one million+ speakers) among the roughly estimated 2000 African languages. However, there are many smaller, still viable languages in which the Scriptures either do not exist at all, or they are available (in part) only in a hard-to-understand missionary version.

9. For a more detailed historical survey, see Wendland 1998:ch.1 and the references cited there (cf. also Wilt 2003:259-262). All quotations in the present section are taken from this larger study. There are rumors that a fourth, the newest, translation is in progress - in the style of the Living Bible - but I have not yet seen any evidence of this. 
This story begins towards the end of the $19^{\text {th }}$ century when the first translated texts were produced in the Chimang'anja dialect of what later came to be known as Chinyanja by early Scottish missionaries of the Church of Central Africa Presbyterian (CCAP) ${ }^{10}$ One of the early pioneers in this effort, Rev. DC Scott, was of the opinion that "language is the poetic or creative attempt of a people to incarnate will and spirit in sound and word" and that the various Bantu vernaculars of east-central Africa also "performed an equally necessary, though inadequate function in mediating the mystery of God." He further declared with some enthusiasm that:

the [Chinyanja] language ... is broad and delicate in its conceptions... [fit] for a high place in the kingdom of heaven; and any who would surpass it must be as broad and courteous as this language and this people declare the genius of Africa to be...

Due to the persistent efforts of Scott, the four gospels were published in 1893 and the entire New Testament followed shortly thereafter in 1896. The problems inherent in any "one man" Bible translation must have soon become apparent, for a revision project was undertaken by a small committee of missionaries and national teachers early in the new century. This revised New Testament appeared in 1906, and work on the much longer Old Testament was begun under the leadership of Rev. W Murray. The first edition of the entire Bible, the Buku Lopatulika, was not ready for publication until 1922 (produced by the British and Foreign Bible Society). Various minor revision projects, including the addition of sectional headings and more extensive textual cross references, were carried out in the ensuing years, right up until a final major alteration to the orthography in 1966.

The $B L$ was widely accepted and became in effect "the Bible" for all Chinyanjaspeaking Protestant Christians in the central African region, even achieving in recent years a status akin to the venerable King James Version in English. Linguistically, it was also a great accomplishment because it was a generally successful "union version," composed as an amalgam of closely related dialects (but favoring the original southern variant) of the language that later became known and taught more officially as Chinyanja ("the language of the lake," i.e., Nyasa/Nyanja, now Lake Malawi). Two other features of this translation, however, are much less positive in their overall communicative effect: First, the $B L$ was an extremely literal rendering that corresponds very closely to the wording of the KJV; second, the text was obviously composed and finalized by non-mother-tongue speakers since it is quite unnatural-sounding in very many passages. The result is that the $B L$ rendition, though familiar to a majority of Christians in terms of the form of language is very difficult to understand with regard to the intended content of Scripture. Thus for all who read and hear this Bible, "God" (Mulungu/Yehova) and his messengers speak with a very heavy foreign accent!

Inter-church rivalries being what they were in the early $20^{\text {th }}$ century, it is not surprising that portions of a second Chinyanja version of the Scriptures soon began to appear in print. The Malembo Oyera thus grew out of a long-standing desire for Roman Catholics to have their own Bible, one based largely on the Latin Vulgate that would also include the socalled "Apocryphal" (or "Deuterocanonical") books. This too started out very much as a one-man translation project, the dream of a French White Father, Fr. Louis Villy. Progress

10. Chimang'anja is the principal southern Malawi dialect of Chinyanja; Chichewa is spoken in the central region and Chipeta in the western part of the country (formerly Nyasaland; cf. Heatherwick 1929:v-vi). Other, minor dialects are mentioned by early commentators, but they are not always clearly distinguished from one another, nor are their interrelationships specified. Additional dialects of Chinyanja are spoken in Zambia and Mozambique, but I will focus on the majority Malawian version, especially since Nyanja Bible translation activities were initiated and carried on mainly in Malawi. 
was slow, and the Gospels plus Acts did not appear until the 1930s. Fr. Villy's poor health further delayed his progress, but the full Bible was finally published in 1966, with the editorial assistance of Fr. (later Bishop) Patrick Kalilombe. This translation featured several important supplementary aids for readers in the form of individual book introductions and periodic explanatory footnotes. The $M O$ was not quite as literal a rendering as the $B L$, and although it served the Catholic Church very well for over 30 years, most people recognized that "it was still the work of an expatriate and ... that it was possible to go one step further - to have a translation made by a team of Malawians, using the type of language spoken by the people" (Fr. Noel Salaun).

Work on a new, ecumenically-supported translation, the Buku Loyera, was sponsored by the United Bible Societies in the 1960s. This version, composed by mother-tongue translators (most notably, the Chinyanja language scholar Fr. Joseph Tenthani $\$$ ), was not intended as a replacement for either the $B L$ or the $M O$, but it was designed to be a complementary, "popular language" Bible, one that would express the essence of the Word of God in a natural Chinyanja verbal style. The aim was also to produce a text of Scripture and religious terminology that would be acceptable to and used by the members of all churches, thus unifying the Christian community both within the country and beyond Malawi's borders (wherever Chinyanja is spoken). A wide variety of serious orthographical, exegetical, and translational problems had to be confronted, thoroughly debated, and resolved through compromise during the 30 -year history of this joint translation project. These ranged from the mundane to the momentous - for example, from petty lexigraphical interference initiated by the Office of the Malawian President (the self-styled linguist, Dr. Kamuzu Banda) to differences over the translation of the holiest name for God in the entire Bible - the so-called "tetragrammaton" (i.e., the Hebrew $\eta \omega \eta \psi$ or $Y H W H$ ). The latter issue could not, for church "political" reasons, be decided in favor of either the current Protestant or Catholic choices, namely, Yehova or Yahve. Instead, a local "transculturated" term was chosen, the personal name of the Chewa Creator and RainMaker, Chauta (cf. Wendland 1998:115-121).

The New Testament of the $B Y$ was first published by the Bible Society of Malawi in 1977, but it took another 20 years before the full Bible appeared (1998) in both Catholic and Protestant versions (the former including the Deutercanonical books, the latter not). This localized translation has been enthusiastically received in some, mainly Catholic circles but has sparked controversy in other, largely Protestant churches, namely, those that tend to reject idiomatic, vernacular-oriented translation principles and the changes that these necessarily occasion in older, more familiar (i.e., $B L$-based) terminology. Another prominent example of such stylistic and conceptual disagreement concerns the key biblical word "grace" (Greek $\chi \alpha \rho ı \zeta)$ - the beloved noun chisomo "good fortune" (CD 2000:65) versus $B Y$ 's figurative verbal paraphrase kukomera mtima "to be pleasant-hearted towards [someone]" (cf. Wendland 1998:124-129). The BY version has incorporated many other features to assist readers in their task - that is, in addition to the cross references, short introductions, and explanatory footnotes mentioned above, a more legible print format (e.g., larger letters), selected informative illustrations, maps/charts, glossary entries, and a topical index. These extra-textual helps will be greatly expanded, especially the footnotes, and certain text revisions included in a new "study Bible" edition that is currently being prepared in Malawi (cf. Wendland 2000). 


\section{Bible Translation as a Linguistic-Literary Development Agency in and for Chinyanja}

The preceding historical survey has suggested a number of ways in which Bible translation has served as both a library of preservation and also an illuminating lighthouse with respect to the Chinyanja language-culture and its literature. ${ }^{11}$ I will now summarize some of the most significant aspects of these two distinct, but interrelated functions, which are so vital for facilitating and promoting current vernacular communication. I have included examples to illustrate several of the major problems and possible solutions that appear in connection with the great challenge of Scripture translation. In the process, various pros and cons of two radically different translation techniques will also become apparent through a comparison of the $B L$ and $B Y$ versions, which are the most disparate in usage.

\subsection{The "Library" Function}

In the first place, Bible translation and related activities may be viewed as functioning like a library in the preservation of the Chinyanja language and its associated (en-verbalized) culture. This process undoubtedly began with early efforts to reduce the spoken language to writing, which was carried out on many fronts and by different agencies, both religious and secular, in the latter part of the $19^{\text {th }}$ century. While I have not seen any official records to this effect, there must have been fairly widespread agreement on the orthography issue by the time of the publication of Scott's magisterial A Cyclopedia Dictionary of the Nyanja Language Spoken in British Central Africa (cf. 1892:ix). The relative linguistic stability that was achieved during this period is attested by Heatherwick's edited revision of Scott's work in 1929 (612 pages of small print!), using virtually the same system of spelling for the all of the lexical entries that were retained. In his Preface, Heatherwick makes the noteworthy comment:

Mang'anja, or, as it is now called, Nyanja, has come to occupy the place of a lingua franca. ...Though spoken over a wide area and by people differing in many ways both in habits and customs, the Nyanja language presents few dialect variations ... mostly [those] in accent and intonation. ...In the meaning and use of various words, however, there will be found some marked differences. ... This presents some difficulty in the compilation of a dictionary of the language as a whole (ibid:v-vi).

The early Bible translators faced this same dilemma of dialect - hence their effort to produce a linguistic "union version". Indeed, it is a testimony to their success in this regard: (a) that the Buku Lopatulika achieved such widespread popularity, and (b) that only a comparatively small percentage of its vocabulary is completely unknown to older mother tongue speakers today. ${ }^{12}$ The Bible surely must have contributed to a standardization of Chinyanja's lexical and grammatical usage over the years. Its stabilizing influence continued during periods of linguistic change due to interlingual contact (e.g., the formal and informal influx of English) as well as revision, particularly during the days of Dr. Kamuzu Banda, who fancied himself as something of a "Chichewa" language expert and

11. Martin Luther, almost single-handedly, performed a similar function for the German language and literary culture in the 1500s (for a survey, see Wendland 1995).

12. Unfortunately, this percentage is increasing rather rapidly nowadays, especially in urban areas throughout east-central Africa, due to a general decrease in emphasis on the use of local languages, coupled with a corresponding rise in the perceived prestige and utility of English. 
was not hesitant about expressing his opinion, which of course immediately became a law that was strictly enforced in Malawi. ${ }^{13}$

In addition to the formal linguistic elements of the Chinyanja language, the three Bible translations also served to record and preserve many conceptual features important to the speakers' culture. In their struggle to find verbal equivalents for the diverse literature of the Scriptures, the translators had to be scholarly, precise, resourceful, creative, and flexible in their approach. Indeed, it is quite amazing to see some of the solutions that the $B L$ version manifests in the initial, ground-breaking struggle to trans-form the many alien concepts, technical terms, and culture-specific expressions of the biblical text into a local language, e.g., "conscience" => cikumbu mtima ("heart-reminder, recollection" in Romans 9:1, generalized to mtima "heart" in $B Y$ ); "cubits" => mikono ("[fore]arms" in Genesis 6:15, modernized to the anchronistic mamita "meters" in BY); "slave guardian" => namkungwi (traditional "initiation instructor" in Galatians 3:24, retained in $M O$ and $B Y$ ). Literal the text may be, but the words are still Chinyanja, and that creates at least the potential for understanding - when supported by supplementary instruction - in place of having nothing at all, except perhaps for on-the-spot oral translations of some English Bible (which is how the first missionaries undoubtedly had to start out).

Since Bibles, or various portions thereof, were the normally the most prominent and authoritative publications in many east-central Bantu languages during the early British colonial period (at times the only generally acceptable and available material in print), they had a great influence on the development of other types of literature - certainly most religious publications and often nascent secular vernacular newspapers as well. Early Malawian and Zambian authors, broadcasters, and politicians tended to be either active Christians or they had been trained primarily in mission schools. Hence, they too frequently gave evidence of the influence of the Scriptures (or its distinctive literary register, Chibaibulo "Bibelese") in their formal oral and written discourse. Due to the high reverence that people had for the "word of God," this aspect of the preservative function of Bible translation did not always turn out in the best interests of the language. In other words, since people, the authorities in particular, were reluctant to replace or modify standard ("sacred") biblical usage, many awkward, confusing, and erroneous expressions continued to circulate despite the urgent need for change. One obvious instance of this would be in the borrowing of English proper nouns or the spelling of personal names, which normally tended to follow their vernacular biblical correspondents no matter how mistaken phonologically or inconsistent in terms of orthography, e.g., Babulo for "Babylon" (cp. Babilone in $M O$ and Babiloni in BY; cf. Baibulo "Bible"); Solomo for "Solomon" (cp. Salomoni in MO and Solomoni in BY).

Different Bible translations, both olden and modern, served not only directly as a cumulative repository and a thesaurus for the Chinyanja language and literature, but they also functioned to stimulate other projects that performed a similar preservative function. The three vernacular Bibles were preceded and followed by a sizable sequence of

13. An example of this is his arbitrary pronouncement that "the letter $c$ should always be followed by the letter $h$ " despite the fact that "when the glottal fricative $-h$ - is combined with $c$ - there is no aspiration" (Chichewa Orthography Rules, rev. ed. of 1990, pp.1,15). Among other pronouncements, Banda also changed the longstanding name of the language from Chinyanja to Chichewa, perhaps because he was a speaker of the latter dialect of the Nyanja cluster. This action caused considerable confusion in the region for some time (the name has recently reverted to Chinyanja). Apparently the only linguistic training that Kamuzu Banda had was gained informally while he was attending the University of Chicago (USA) and was hired (or volunteered?) to serve as the chief language "informant" for Watkin's dissertation on "Chichewa" (1937), which turned out to be rather inferior in terms of its academic quality. 
grammars, dictionaries, wordbooks, scholarly journal articles, dissertations, and diverse collections of stories, proverbs, riddles, and songs. Often, especially in the early years, these were researched and produced by missionaries who were somehow connected with Scripture translation. Later on, more and more trained national scholars became engaged in such activities, either as (co)authors or as essential assistants, for example, Bishop (Rev. Dr.) Patrick Kalilombe in Malawi (e.g., 1999). These mother-tongue experts corrected or built upon the initial work of foreign speakers to ensure that important linguistic and sociological information which is more accurate, relevant, and insightful is preserved for future generations. A major undertaking in this regard is the new "study Bible" project that is currently being produced by the Bible Society of Malawi (cf. Wendland 2000). National Chinyanja-speaking editors and reviewers are thus preparing a text that will contain biblical explanatory notes pertaining to many different aspects of Bantu culture, both past and present, that are specific to this central region of Africa. ${ }^{14}$

\subsection{The 'Lighthouse' Function}

I will now discuss a second noteworthy language-enhancing function of Bible translation, that is, over and above its primary operation as a sacred, religious text for believers. This is its service as a lighthouse to illumine certain critical aspects of Chinyanja's linguistic and cultural growth and development over the years. Such "enlightenment" may be viewed as having a negative as well as a positive orientation - namely, to reveal certain problems inherent in past studies of this multifaceted subject and also to show the way forward along a surer path to new discoveries and conclusions within this same general ethnological framework.

Such post-independence initiatives in favor of vernacular studies were hindered, however, due to increasing competition from English-biased disciplines and professions (i.e., where the money and personal advancement lay). In any case, it is important to point out the ongoing contribution that was made in the diverse fields of orthography, lexicography, linguistics, socio-anthropology, literature, historiography, folkloristics, and other culture-engaging endeavors by Malawians and Zambians who were in some way associated with the practice of Bible translation, in particular, the Buku Loyera interconfessional project (ca. from 1965 to date). Within the confines of this article, I cannot survey the progress being made in all of these academic fields; rather, I will focus my attention upon the manifold stylistic enrichment of the Chinyanja language as reflected in the published text of the $B Y$.

The early (and later) expatriate researchers, writers, and commentators on Chinyanja (including the present author, e.g., 1976) were obviously limited in their ability to fully or correctly perceive and interpret the various phenomena that they were observing. It remained, as already noted, for national scholars to take up the challenge (once given the opportunity and requisite training) to rectify outstanding errors, distortions, or misunderstandings and to continue building the knowledge base from there. This is most obvious perhaps in the area of biblical terminology, especially in cases where concepts alien to the local thought-world and realm of personal experience are being referred to. For example, the older versions illustrate two divergent approaches to the translation of "temple," each problematic in its own way. Surprisingly, $B L$ employed a vernacular "transculturation" - kachisi; the difficulty here is that this word designates a completely

14. Three experienced Malawian "pastoral" academics comprise the current editorial team based in Zomba: Rev. Dr. Joel Manda (Coordinator), Rev. Dr. (Bishop) Patrick Kalilombe, and Rev. Dr. Frank Chingota. The first trial annotated portion of Luke ( $L u k a$ ) is scheduled to appear in print early in 2003 with Acts (Ntchito za Atumwi "Works of the Sent Ones") to follow later in the year. 
different type of construction, namely, a small temporary grass-and-stick shelter that functions as a prayer shrine for the ancestral spirits. $M O$, on the other hand, went for the expected "transliteration" (from English) - Tempile, which of course depends upon subsequent (correct) instruction to elucidate its meaning. $B Y$, perhaps for church diplomatic reasons, could not chose either of these alternatives (though Tempile was the only valid possibility) and coined a descriptive phrase instead - Nyumba ya Mulungu (ya ku Yerusalemu) "the House of God (in Jerusalem)."15 The Jewish "synagogue" is distinguished in BY as nyumba yamapemphero (ya Ayuda) "the house of prayers (of the Jews)" (cf. BL/MO: sunagoge). ${ }^{16}$

A literalistic methodology also crippled the pioneer translators in terms of flexibility since most Hebrew and Greek terms tend to be rendered concordantly, irregardless of the context. This procedure frequently results in an unintelligible text, e.g., "and my glory rejoices" (Psalm 16:9) becomes nukondwera ulemu wanga "and my honor/self-respect is happy" in $B L$, which is quite meaningless (cf. BY: ndipo m'katikati mwangamu ndikusangalala "and in my innermost [being] I am rejoicing"). The correction of the $B Y$ text illustrates the creative translation technique that the later Malawian nationals adopted towards the challenge of transforming an alien text and thought-world into a dynamic manner of perception and expression in Chinyanja. A similar conceptual problem is occasioned for the same reason in Romans 8:15. In this case I will cite a back translation of this entire passage in both the $B L$ and the $B Y$ in order to reveal also the considerable hermeneutical skills of Fr. Joseph Tenthani, the latter's principal translator. The theological concepts as expressed in the biblical text are extremely concentrated and rather complicated as well, but observe how they are unpacked in the $B Y$ rendition:

For you did not receive a spirit [ancestral?] of slavery (or: "enslaved spirit" mzimu wa ukapolo) to cause fear again; but you received a spirit of childhood (or: "childlike spirit" mzimu wa umwana), which we shout with it, saying, Abba, Father. $(B L)$

As you know, the Spirit [implied: wa Mulungu "of God"] whom you received does not transform you into slaves so that you continue to remain in fear, no at all. But that Spirit transforms you into the children of God (amakusandutsani ana a Mulungu), and so, in his power, when praying to God, we say, "Abba! Father!" $(B Y)$

As it stands, the text of the $B L$ is almost incomprehensible to any reader (certainly to all hearers) who does not have immediate access to the Greek original. $B Y$, on the other hand, brings out the intended sense clearly, employing contemporary Chinyanja usage.

It is a truly a verbal delight then simply to read this new translation aloud so as to hear how natural and euphonious in speech, at times highly emotive and colloquial, it actually sounds - especially in the dialogue portions of Scripture where the difference becomes even more evident. The following selection well illustrates this, although it can be fully appreciated only by mother-tongue speakers of Chinyanja; for the others, I have underlined a selection of the key idiomatic expressions, that is, where significant stylistic improvements are evident in comparison with the linguistic expression as found in the $B L(M O)$; the twelve specific items in boldface highlight important translational procedures that complement the text's linguistic naturalness (these are identified in the footnotes). This example is a portion of the dramatic exchange recorded in John 9 (vv. 24-34):

15. The words in parentheses may be included on first mention in a particular context, but the abbreviation is normally used thereafter.

16. Such a glossary entry in $B Y$ normally points out the different usages among the three Chinyanja versions where key terms are concerned, thus encouraging a growth in the vocabulary at large. 
Pamenepo Ayuda aja adamuitana kachiwiri

munthu uja kale sankapenyayu,

namuuza kuti,

"Lemekeza Mulungu, ndipo unene zoona.

Ife tikudziwa kuti munthu amene uja ngwochimwa."

Iye adati,

"Zakuti Iye ngwochimwa, ine sindikudziwa.

Chinthu chimodzi chokha ndikudziwa,

kuti kale ndinali wosapenya,

koma tsopano ndikupenya."

Iwo adamufunsa kuti,

"Kodi anachita chiyani pamene anakupenyetsa?"

Iye adati,

"Ndakuuzani kale, koma simumasamalako.

Nanga chifukwa chiyani mukufuna kuzimvanso?

Kapenatu nanunso mukufuna kukhala ophunzira ake eti?"

Pamenepo iwo adayamba kumlalatira, adati,

"Wophunzira wake ndi iweyo.

Ife ndifetu ophunzira a Mose.

Tikudziwa kuti Mulungu adalankhula ndi Mose,

koma uyu sitikudziwa kumene wachokera."

Munthuyo adati,

"Pakudabwitsatu mpamenepa,

kuti inuyo simukudziwa kumene Iye wachokera,

komabe wandipenyetsa.
Then those Jews ${ }^{17}$ summoned for a second time

that very man who formerly ${ }^{18}$ could not see,

and they told him,

"Praise God, and tell the truth now. ${ }^{19}$

"We know that that fellow is sinful."

He said,

"That he is a sinner, I do not know.

One thing only I know,

that formerly I was blind,

But now I can see." 20

They asked him,

"What did he do when ${ }^{21}$ he made you see?"

He said,

"I told you already, but you pay no heed at all. ${ }^{22}$

So why do you want to hear it again?

Could it be that ${ }^{23}$ you too want to become his disciples?"

Then they began to revile him, saying, "You are the one who ${ }^{24}$ is his disciple.

As for us, we are the disciples of Moses.

We know that God spoke with Moses,

But this one, we don't know where he comes from."

The man said,

"That is most amazing, ${ }^{25}$

that you do not know where he comes from, and yet he made me see (gave me sight).

17. A full noun phrase elucidates the original Greek pronominal antecedent (copied literally in $B L$ and $M O$ ).

18. The added adverb makes it explicit that this man was no longer blind, as implied in the other versions.

19. The initial exclamation ("praise God!") must be specified as to its affective function, i.e., to strongly adjure the addressee.

20. Observe the rhythmic parallelism of the Chinyanja text, i.e., the utterance-final verb pairs, -dziwa and -penya.

21. Two short queries in the original, the first ambiguous, are combined into one here, for greater clarity.

22. The early, literal translations suggest that the Jewish leaders could not hear or understand what the man had told them; the present rendering shows that their ignorance was a matter of deliberate choice.

23. The added particles in $B Y$ convey the barbed sarcastic connotation of the man's rhetorical question.

24. The word order of $B Y$ highlights the essential contrast that underlies the Greek text.

25. An initial Chinyanja idiomatic and intensified expression emphasizes this man's reply of rebuke. 
Timadziwa kuti Mulungu samvera anthu ochimwa. We know that God does not listen to sinners,

Koma munthu akasamala za Mulungu,

But if a person cares for the things of God, ${ }^{26}$

nachita zimene Mulungu afuna, and does the things that God desires,

Mulungu amamumvera.

Nkale lomwe sikudamveke konse kuti

God listens to him.

wina adapenyetsetsa munthu wakhungu.

Never before has it been heard that

anyone caused a blind person to see.

Munthu ameneyu akadapanda kuchokera kwa Mulungu,

sakadatha konse kuchita kanthu."

Iwo adati,

"Iwe udabadwa m'machimo okhaokha.

Ndiye iweyo nkutiphunzitsa ife?"

Atatero adamtulutsa nkumudula ku mpingo.

If this man had not come from God,

he could not have done anything."

They said,

"You were born completely in sins. ${ }^{27}$

Do you really think that you can teach us?"

After saying that, they expelled and excommunicated him. ${ }^{28}$

The preceding examples illustrate that it is the "little things," along with the major linguistic adjustments, that make an appreciable difference in verbal discourse, oral or written, whether an original composition or its translation. Such subtle, sophisticated stylistic features were either not used at all or they were mis-used in the older versions, for example, Chinyanja's elaborate deictic-referential concordance system (a host of attached clitics), precise verbal tense patterns, and diverse, pragmatically governed word order variations. Notice too the text's composition in the form of "rhythmic utterance units" to facilitate both its oral articulation as well as its aural apprehension. Other passages illustrate $B Y$ 's utilization of additional idiomatic devices, such as, figures of speech (especially similes/ metaphors), indigenous lexical collocations, rhetorical intensifiers, phonological underscoring (e.g., alliteration), punning, rhythmic pacing and phrasing, exclamations, and ideophones. Listen, for example, to Christ teach - aloud - as if he were a Chinyanja-speaking wise-man (in Matthew 6:21, 23b):

Pajatu kumene kuli chuma chako, mtima wakonso - kokhala nkomweko!...

Tsono ngati kuwala kumene kuli mwa iwe kusanduka mdima,

mdima wakewo ndi wochita kuti goo!

As you know, where your wealth is, your heart too - that's right where it resides! ...

Now if the illumination that is inside you turns into darkness,

that very darkness is GOO! - as dark as a moonless night.

Such artful verbal features, their depth and diversity at least, could easily be lost to the next generation of speakers, but they are distinctive characteristics of the spoken language that are being introduced into printed discourse by creative mother-tongue authors - and

26. The expression found in $B Y$ removes the ambiguity of the original (and the $M O$ and $B L$ versions).

27. Another Chinyanja idiom here clarifies the sense of the biblical text.

28. The additional verb in $B Y$ reveals the full religious implication of "expelling" someone from the temple. 
translators. ${ }^{29}$ A much fuller use of the rich verbal resources of the vernacular is made in $B Y$ (in comparison with the two earlier versions), therefore also preserving along with the familiar wordings also their associated indigenous concepts. Modern Bible translation thus performs both a vital preservative as well as a stimulating language promotional function.

Of course, the translators of Scripture must also be very sensitive to public opinion. They must take care not to go too far or too fast in the direction of "modernism" or the "youth (pop) culture" with regard to language use lest they inadvertently provoke listeners to react negatively, or even with outright rejection, especially when the Scriptures are read in public worship. The biblical text must never sound substandard or too undignified for church settings! For this reason much text testing and audience sampling must be conducted on a systematic and ongoing basis to ensure that the translation keeps in step with its intended audience. Such research also serves to generate personal interaction with local communities regarding language usage and user attitudes, both formal (e.g., issues of orthography) and semantic (e.g., the expression of crucial or controversial theological concepts).

\section{Conclusion: Planning and Training for the Future}

Early modern missionaries ... followed the logic of the translatability of Christianity and submitted the religion in the most intimate way to the terms of local culture. By doing so, such missionaries had become indigenizers in the best sense of the term, rather than cultural imperialists. Translation thus brought Christian mission into an original congruence with the vernacular paradigm, with a tacit repudiation of Western culture as the universal norm of the gospel (Sanneh 1989:90).

While I would generally agree with Sanneh's preceding assessment of the situation, at least in terms of my own experience in east-central Africa, I think that a significant qualification might be in order: This so-called "vernacular paradigm" was (and is) able to reach its full potential in application only when the "librarians" and "lighthouse keepers" happen to be qualified, well-trained mother-tongue speakers of the local languages. In cases where non-nationals still man these crucial positions, the possibility of misunderstanding and misdirection remains, that is, with respect to either the language or its culture. It follows then that more African translators and theologians undoubtedly need to be empowered both through education and the provision of adequate resources so that they can carry forward the various mandates of mission and the church into the new millennium. It is encouraging to see that many Bible translation agencies on the continent (e.g., United Bible Societies, Wycliffe Bible Translators, Word for the World) clearly recognize this necessity and have already begun putting into place various programmes to achieve a higher standard of translator training on all levels of service, from local village text reviewers to the creation of a corps of African translation, technical, and management consultants.

My little case study also illustrates the great value of intensive historical study and documentation for future reference and instruction. From the "library" of history, oral as well as written, language planners and promoters can, with practice, learn to learn from both past mistakes and also proven solutions, for example, in the area of orthographic representation and lexicographical (dictionary) studies. On the other hand, the earlier impediments to progress that were periodically occasioned either by missionary manipulation, denominational rivalries, church separatism, inter-ethnic intolerance, or political

29. For an excellent overview of the potential for skillful translators to be creative as well as effective in their work - to "perform," as it were, "without a stage" - see the recent study of Wechsler (1998). 
interference should be strongly avoided. On the contrary, specific jointly-engaged and administered projects such as the ongoing revision of the recent inter-confessional Scripture translation $(B Y)$ must be vigorously encouraged. Such endeavors will hopefully serve, in addition, to reveal some of the principal future needs and critical problem areas in the broader domain of language-culture development, e.g., the nature, rate, and impact of foreign linguistic or literary interaction and "borrowing". This would certainly benefit not only the members of a major language like Chinyanja, but also, through cooperative engagement, the speakers of related languages who would be able to learn and profit from the lessons and good models to be found in the historical development of the former. This might include, as noted earlier, the production of supplementary tools like a user-sensitive, locally contextualized "study Bible".

Bible translation and related ventures can also perform a valuable "lighthouse" function to illumine the path towards the development of new resources that will promote African languages, literatures, and cultures in general. Some of these would be human facilitators such as linguists, writers, broadcasters, scholars, and other vernacular-based experts or master performers. Having participated in an intensive, well-organized and managed programme of Bible translation, men and women learn by experience and are well prepared later, once a given project has been completed, to serve in other important capacities, both religious and secular, that can contribute to different facets of nation-building. In addition, larger Bible translation agencies often bring the members of different ethnic groups together for conferences and workshops where they find (often) rare opportunities to share histories, resources, experiences, insights, and visions for the future. Through such meaningful contact, one group can serve to stimulate, encourage, correct, or even empower another along a common path towards progress in various fields of other human endeavor social, educational, artistic, academic - that is, in addition to "the spiritual".

Over the past several decades, many Bible translation organizations have also been in the forefront of some new and exciting developments in the area of alternative communications. Nowadays the Scriptures are no longer limited to a thick black book requiring considerable literacy and other skills to access it. Rather, the way has been lit for many other media and means to get the message across - for example, through comic books (especially for the younger generation), audio Scriptures (for those who cannot read), video formats (for people who cannot take time to read), radio and television productions (which broadcast to a much larger, often remote audience), and electronic programs (to cater for an increasingly "computerized" age). Of course, funding is always limited, and therefore it would not be possible for such culturally enriching projects to be undertaken in or for smaller language groups - at least not right away. However, sometimes all it would take is a multifaceted success story in a major language that - having proven the point and blazed the trail - could serve as a model as well as a resource for others. In such cases, the producers and technicians of one language could readily be called upon to set the ball rolling in another. Translating the Scriptures in all of its possible styles and available media provides a natural forum or agency for initiating these and related activities within any language group, but especially in those that may have been neglected in the past - even in the post-"independence" years of nationhood.

But is there not a potential danger here to "nation-building" and the essential unifying of its diverse peoples, cultures, and tongues - that is, if too many smaller groups are encouraged in different areas of vernacularization? Indeed, in some African countries a dominant national language-culture has been zealously promoted at the expense of others, ostensibly for this very reason - to promote the unity of the whole (the examples are wellknown and need not be mentioned). It is debatable though whether such an exclusivist 
policy can really be successful in the long term and where a large ethnic convergence is concerned. In fact, many researchers would argue persuasively against any monolithic approach to language planning and development within a country. Unity is created instead through interactive diversity - that is, where there is also mutual cooperation and a high level of common management. This argument is complex and perhaps controversial in certain of its aspects; therefore, it will not be considered further here.

However, a strong case can be made in support of two fundamental facts - one general, the other specific. First, an enlightened, informed, cooperative, and balanced linguistic programme on the national level can indeed function to forge a formidable unity out of considerable diversity; Switzerland is a case in point (is South Africa another instance in the making?). Second, most educators agree that primary schooling is carried out most efficiently and productively when it occurs originally in the child's mother tongue. That in itself should encourage the development of all minor as well as major languages within a given macro speech community. But the key here, as in most human endeavors, is a cooperative, integrated approach to planning and implementation that is based on mutual respect. Thus, any such multi-language promotional venture must occur as part of a comprehensive, systematic, well-coordinated, and sufficiently funded strategy on national as well as on state and local levels.

Therefore, Bible translation agencies should be ready and willing to collaborate with any other religious body or even the appropriate government ministry to work towards the ultimate success of all such language-culture enhancing and communication enriching efforts. After all, from our perspective it is the very same divine Word at stake in each and every language-culture world-wide - and that is a unifying factor which inspires the utmost motivation. Therefore, we may expect the work of translating the Scriptures, in various forms and formats, to continue to play an important role in serving both as a library as well as a lighthouse for the preservation and promotion of African languages and cultures in the $21^{\text {st }}$ century (and beyond?). 


\section{BIBLIOGRAPHY}

Barrett, DB 1968. Schism and Renewal in Africa: An Analysis of six Thousand Contemporary Religious Movements. Nairobi: Oxford University Press.

Chinyanja Dictionary (CD - Mtanthauzira mawu wa Chinyanja) 2000. Zomba: Centre for Language Studies, University of Malawi (Dzuka Publishing).

Heatherwick, A 1929 (1951). Dictionary of the Nyanja Language. London: Lutterworth Press for the United Society for Christian Literature.

Kalilombe, PA 1999. Doing Theology at the Grassroots: Theological Essays from Malawi (Kachere Book No. 7). Gweru: Mambo Press.

Katan, D 1999. Translating Cultures: An Introduction for Translators, Interpreters and Mediators. Manchester: St. Jerome.

Neusner, J and Green, Wm S (eds.) 1996. Dictionary of Judaism in the Biblical Period. Peabody: Hendrickson.

Nida, EA and Taber, C 1969. The Theory and Practice of Translation. Leiden: E J Brill.

Sanneh, L 1989. Translating the Message: The Missionary Impact on Culture. Maryknoll: Orbis Books.

Scott, DC 1892 (1968). A Cyclopaedic Dictionary of the Nyanja Language spoken in British Central Africa. Edinburgh: Foreign Mission Committee of the Church of Scotland (republished by Gregg International, Westmead, England).

Watkins, MH 1937. A Grammar of Chichewa. Language Dissertations 24, 1-158.

Wechsler, R 1998. Performing without a Stage: The Art of Literary Translation. North Haven: Catbird Press.

Wendland, ER 1976. Nthano za kwa Kawaza ('Folktales from Kawaza-Land'). Lusaka: Zambia Language Group (UNESCO-sponsored Project).

Wendland, ER 1995. Martin Luther, the Father of Confessional, Functional-equivalence Bible Translation [Part 1]. Notes on Translation 9/1, 16-36.

Wendland, ER 1998. Buku Loyera: An Introduction to the new Chichewa Bible Translation (Kachere Monograph No.6). Blantyre: CLAIM.

Wendland, ER 2000. Contextualising Bible Reading in South-Central Africa: The Preparation of an Annotated Edition ('Study Bible') - with Special Reference to the Gospel of Luke in Chichewa. Neotestamentica 34/1, 143-171.

Wendland, ER 2002. Towards a 'Literary' Translation of the Scriptures. In Naude, JA and van der Merwe, CHJ (eds.), Contemporary Translation Studies and Bible

Translation: A South African Perspective. Acta Theologica Supplementum 2, $164-$ 201.

Wilt, T (ed.) 2003. Bible Translation: Frames of Reference. Manchester: St. Jerome. 